Der folgende Text wird über DuEPublico, den Dokumenten- und Publikationsserver der Universität Duisburg-Essen, zur Verfügung gestellt.

Diese auf DuEPublico veröffentlichte Version der E-Publikation kann von einer eventuell ebenfalls veröffentlichten Verlagsversion abweichen.

Iannaccone, Antonella; Tyczynski, Bartosz; Birdir, Cahit; Enekwe, Antje; Kimmig, Rainer; Köninger, Angela:

The Use of Plasma Exchange in a Very Early-onset and Life Threatening, Hemolysis, Elevated Liver Enzymes, and Low Platelet (HELLP) Syndrome

URN: urn:nbn:de:hbz:464-20161221-124744-6

PURL / DOI: http://dx.doi.org/10.4172/2161-0932.1000387

WWW-Link: http://duepublico.uni-duisburg-essen.de/servlets/DocumentServlet?id=42990

Rechtliche Vermerke:

This is an open-access article distributed under the terms of the Creative Commons Attribution License, which permits unrestricted use, distribution, and reproduction in any medium, provided the original author and source are credited.

Quelle: Gynecology \& Obstetrics, 2016, 6:6; Published Date: June 27, 2016 


\title{
The Use of Plasma Exchange in a Very Early-onset and Life Threatening, Hemolysis, Elevated Liver Enzymes, and Low Platelet (HELLP) Syndrome: A Case Report
}

\author{
lannaccone $A^{1,2^{*}}$, Tyczynski $B^{1,2}$, Birdir $C^{1}$, Enekwe $A^{1}$, Kimmig $\mathbf{R}^{1}$ and Köninger $A^{1}$ \\ ${ }^{1}$ Essen University Hospital, Clinic for Obstetrics and Gynecology, Germany \\ ${ }^{2}$ Essen University Hospital, Clinic for Nephrology, Germany
}

"Corresponding author: lannaccone A, Department of Obsterics and Gynecology, Univerisity Hospital of Essen, Germany, Tel: +49 2017233574 ; Fax: +40 201723 3932, E-mail: antonella.iannaccone@uk-essen.de

Rec date: April 30, 2016; Acc date: June 18, 2016; Pub date: June 27, 2016

Copyright: $\odot 2016$ lannaccone A, et al. This is an open-access article distributed under the terms of the Creative Commons Attribution License, which permits unrestricted use, distribution, and reproduction in any medium, provided the original author and source are credited.

\begin{abstract}
Background: HELLP syndrome is a life threatening pregnancy and early postpartum complication. Very early presentation (before the 21st pregnancy week) is rare and represents an extremely difficult situation for patients and physicians. Supportive therapy (magnesium sulfate, antihypertensive drugs and corticosteroids) may be useful to prolong pregnancy; till now the removing of placenta is the only effective therapeutic option. Plasmapheresis may represent a new and efficacious therapeutic option.

Case description: The article reports on a case of very-early onset HELLP Syndrome at the 18th $(17+5)$ week of gestation. It was a challenging clinical and therapeutic case. Since the fetus did not show any signs of growth retardation or pathological Doppler findings, indicating a good fetal prognosis, we used plasmapheresis as an ultima ratio to prolong pregnancy. With plasmapheresis, the pregnancy was prolonged for 20 days. Unfortunately the deterioration of the clinical situation required delivery in the 21 st $(20+4)$ gestational week.

Conclusion: Plasmapheresis allows prolongation of pregnancy with early onset, life threatening HELLPSyndrome.
\end{abstract}

Keywords: Management of early HELLP syndrome; Plasma exchange; Ultrasound; Imitators of HELLP syndrome

\section{Introduction}

The HELLP syndrome occurs in about 0.5 to $0.9 \%$ of all pregnancies and in 10 to $20 \%$ of cases of severe preeclampsia [1]. In about $70 \%$ of cases, the HELLP syndrome develops before delivery [2]. Almost $10 \%$ occur before the 27th week of pregnancy [3]. Presentation before the 20th week of pregnancy is a rare condition [4]. Maternal mortality is estimated from $1.1 \%$ to $25 \%$ [5]. The causes of death are mostly cerebral hemorrhage and disseminated intravascular coagulopathy [6]. Perinatal mortality depends on the gestational week and is estimated between $7.4 \%$ and $34 \%$ due to prematurity, placental insufficiency and abruption placentae [7].

The pathogenesis remains multifactorial and is not completely understood. Immunological maladaptation and aberrant invading trophoblast are involved in the development of both early-onset preeclampsia and HELLP syndrome. Anti-angiogenetic factors are released from the placenta into maternal circulation inducing the symptoms: sFlt-1 (soluble fms-like tyrosine kinase 1 or soluble vascular endothelial growth factor -VEGF- receptor 1) levels are similar in preeclampsia and HELLP syndrome, other mediators like Fas Ligand and endoglin may be responsible for the greater hepatic inflammation and activation of the coagulation system in HELLP syndrome cases [8]. Togheter with the incresed levels of sFlt-1, there are reduced levels of VEGF and placental growth factor (PlGF), resulting in endothelial dysfunction [9].

Weinstein first described this syndrome in 1982 [10]: "H" represents hemolysis, "EL" elevated liver enzymes and "LP" low platelet count. There exists also an incomplete form, with just one or two elements of the triad [1].

Clinical management depends on the gestational age. Delivery is indicated when the syndrome develops after the 34th gestational week. Delivery after 48 hours of evaluation and treatment with corticosteroids appears reasonable between the 27th and 34th week of gestation. If the maternal or fetal conditions deteriorate, delivery should be performed as soon as possible. If the laboratory results or the clinical condition deteriorate, postpartum plasma exchange is reported to improve maternal outcome of severe HELLP syndrome [11].

\section{Case Report}

We present the case of a 28-years-old Caucasian primigravida at 17 weeks and 5 days of pregnancy who was admitted to a local hospital with complaints of nausea, pain in the chest and in the right upper abdominal quadrant. An electrocardiography and echocardiography were performed and these were not pathological. She was then referred to our tertiary referral centre because her laboratory studies revealed probably a very early HELLP Syndrome: platelet count 40/nl (normal range 180-380), $\mathrm{Hb} 10 \mathrm{~g} / \mathrm{dl}(12-15,2)$, ASAT $141 \mathrm{U} / \mathrm{l}(<35)$, ALAT 254 $\mathrm{U} / \mathrm{l}(<35)$, LDH $376 \mathrm{U} / \mathrm{l}$ (120-247), Haptoglobin 0,07 g/dl (0,4-2,4). At admission, the blood pressure was normal $120 / 70 \mathrm{mmHg}$ under the 
Citation: lannaccone A, Tyczynski B, Birdir C, Enekwe A, Kimmig R, et al. (2016) The Use of Plasma Exchange in a Very Early-onset and Life Threatening, Hemolysis, Elevated Liver Enzymes, and Low Platelet (HELLP) Syndrome: A Case Report. Gynecol Obstet (Sunnyvale) 6: 387. doi:10.4172/2161-0932.1000387

Page 2 of 4

administration of methyldopa $250 \mathrm{mg}$ twice daily since 1 week. She denied a history of chronic hypertension, but she had one hypertensive episode during a recovery in a psychiatric ward because of depression one year before the pregnancy. She revealed the use of cannabis up until in the early pregnancy. She denied the use of cannabis or other illicit substances after knowing she was pregnant. She smoked 4 cigarettes a day. The physical examination revealed no jaundice and no evidence of purpura or petechia, no evidence of neurologic abnormalities or edema, and she was able to converse at her baseline mental status. Her deep tendon reflexes were normal. Fetal cardiac activity was appreciated by ultrasound examination, the Doppler studies of the uterine artery showed pathological values: PI left 2,53 and right 3,30 with notching on both sides.

The administration of methyldopa was continued and an intravenous seizure prophylaxis with magnesium sulfate $1 \mathrm{~g} / \mathrm{h}$ as well as steroid administration was started (10 mg Dexamethasone 3 times a day for 2 days).

Considering the early and unusual presentation, a comprehensive process to exclude differential diagnoses was started. The case was interdisciplinary discussed with the colleagues from the departments of internal medicine, nephrology and gastroenterology. An ultrasound examination of the upper abdomen did not demonstrate any pathological relevance in this region. Normal activity of ADAMTS 13 was registered ( $80 \%$, normal range 50-110\%), excluding thrombotic thrombopenic purpura. Renal function was normal (Creatinine 0,6 $\mathrm{mg} / \mathrm{dl}$, normal range $0,6-1,1)$. There was no icterus, no neurological deficits, normal bilirubin levels $(0,8 \mathrm{mg} / \mathrm{dl}$, normal range $0,3-1,2)$, normal level of fibrinogen $(350 \mathrm{mg} / \mathrm{dl}$, normal range $150-400)$, slightly reduced ATIII activity (70\%, normal range $80-120)$ and other coagulation parameters were in normal range. Autoantibodies were in normal range: ANCA IFT $<1: 10 \quad(<1: 10)$, HepIFT $1: 80 \quad(<1: 80)$, Anticardilipin IgM 1,3 and IgG 1,4 (<7 und $<1: 10)$. sFlt- 1 at admission was high, $25292 \mathrm{pg} / \mathrm{ml}$.

After the therapy with corticosteroids, the situation was stabilized and laboratory values were nearly normal (Thrombocytes $170 / \mathrm{nl}$, ASAT 39 U/l, ALAT 136 U/l, LDH 376 U/l). The sFlt-1 value drops to $13410 \mathrm{pg} / \mathrm{ml}$ and the sFlt-a/PIGF Ratio was 353,2). Unfortunatly, 4 days since the admission, the laboratory studies and the clinical condition deteriorated once again.

The blood pressure became higher with edges of $180 / 100 \mathrm{mmHg}$ (Figure 1), hemoglobin fell to $7,8 \mathrm{~g} / \mathrm{dl}$, liver enzymes became higher with ASAT 1141 U/l, ALAT 935 U/l, yGT 124 U/l, LDH 1591 U/l and thrombocytes 19/nl (Figure 2). The urine examination showed a significant proteinuria $(440 \mathrm{mg} / 24 \mathrm{~h})$. A drug screening detected the presence of amphetamines in urine. A chromatography blood test excluded the assumption of such drugs. A forensic evaluation considered it as a false positive urine screening due to cystitis. A pheochromocytoma was excluded.

Blood pressure was kept under control with intravenous application of urapidil (till $20 \mathrm{mg} / \mathrm{h}$ ), metoprolol $47,5 \mathrm{mg}$ twice daily further to methyldopa $250 \mathrm{mg} 4$ times daily. The patient aimed to prolong the pregnancy. The fetus showed normal growth curve with normal fetal Doppler flows (umbilical artery PI 1,40, arteria cerebri media PI 1,31, peak systoloc velocity of $36,9 \mathrm{~cm} / \mathrm{s}$ ) and no signs of any fetal abnormalities. After consulting the nephrologist and obtaining informend consent of the patient, plasma exchange was started.

14 sessions of plasma exchange were conducted in total with the Spectra Optia and Cobe ${ }^{\circ}$ Spectra Apheresis System. The estimate of plasma volume (EPV) was calculated using the formula of Kaplan AA [12] for EPV: EPV $=[0.065 \times$ body weight $(\mathrm{kg})] \times[1$-Hematocrit $]$. For anticoagulation acid citrate dextrose-A (ACD-A) was used. A dialysis catheter was positioned on the right neck. Before starting, prednisolone, clemastine und cimetidine was administrated intravenously. Plasma was replaced with 2,5 1 of fresh frozen plasma form a donor.

First, we noted an improvement of the general condition of the patient and laboratory results (Figure 3). During the plasma-exchange and 14 days after admission, sFlt- 1 concentration in serum drops further to $10100 \mathrm{pg} / \mathrm{ml}$, but also PIGF also drops $(21,7 \mathrm{pg} / \mathrm{ml})$ with an increased ratio of 466,5 . However, since the determination of sFlt/ PLGF-ratio was not clinical routine during the time of therapy, we failed to determine these values daily during therapy.

The clinical condition of the patient, blood pressure and the laboratory findings worsened again (Figure 2). She developed pulmonary edema, dyspnea and the blood pressure was no longer under control with edges of 200/110.

After extensive interdisciplinary discussions, removing the placenta was the only therapeutic option left to improve the HELLP syndrome. Because of the patient's bad condition, an immediate cesarean section was performed at 21st week of pregnancy, after 20 days of hospitalization. The female fetus was delivered which weighted $310 \mathrm{~g}$ with a head circumference of $16.5 \mathrm{~cm}$ and a length of $23 \mathrm{~cm}$. She was assisted by the pediatricians and died 2.5 hours postpartum. The histological examination of the placenta showed very small terminal villi without sufficient vascularization. After the operation, the patient remained in the intensive care unit for 2 days. The further postoperative course was uneventful.

After the delivery, the condition of the patient improved rapidly. At discharge, antihypertensive medication consisted of metoprolol and amlodipine.

\section{Discussion}

This case underlines two important issues in the about management of the very early HELLP syndrome:

- Exclusion process of imitators of HELLP Syndrome and substance abuse

- A new therapeutic option with the plasma exchange

Severe preeclampsia and HELLP syndrome can resemble a number of different microangiopathic disorders, making it a hard challenge for the physician to distinguish between them.

The clinical presentation of HELLP syndrome commonly includes nausea, vomiting, epigastric pain. In $85 \%$ of the cases, the signs and symptoms of preeclampsia such as hypertension, proteinuria, headache, visual changes and edema are also present.

The symptoms of acute fatty liver in pregnancy (AFLP) are almost identical with those of HELLP syndrome, but women with AFLP can rapidly develop liver failure and encephalopathy. Hypertension and proteinuria are more frequent in HELLP syndrome, but only the laboratory can help to better distinguish between the two entities: in AFLP a prolongation of prothrombin (PT) and of activated partial thromboplastin time (aPTT) is present, further ammonia is more frequently elevated and bilirubin and creatinine are always too high. Liver biopsy is recommended as the standard procedure to confirm the diagnosis, but requires an acceptable haemostatic function [13]. 
Citation: lannaccone A, Tyczynski B, Birdir C, Enekwe A, Kimmig R, et al. (2016) The Use of Plasma Exchange in a Very Early-onset and Life Threatening, Hemolysis, Elevated Liver Enzymes, and Low Platelet (HELLP) Syndrome: A Case Report. Gynecol Obstet (Sunnyvale) 6: 387. doi:10.4172/2161-0932.1000387

Page 3 of 4

Microangiopathic disorders such as thrombotic thrombocytopenic purpura (TTP) and hemolytic uremic syndrome (HUS) are extremely rare in pregnancy $(1: 100.000)$.

The classic manifestations of TTP include thrombocytopenia, microangiopathic hemolytic anemia, neurological abnormalities, fever and renal failure with the first three signs present in almost $50-75 \%$ of the cases. In TTP the activity of the von Willebrand factor cleaving metalloprotease known as ADAMSTS-13 is reduced. The elevated levels of large multimeres of the von Willebrand factor induce platelets aggregation and endothelial injuries. Patients with TTP present a strong reduction of ADAMSTS-13 -activity $(<5 \%)$, whereas in HELLP syndrome the metalloprotease activity is normal or just slightly reduced.

HUS is an exceptional event during pregnancy and it is mostly seen in children after enteric infection with E. coli that produces Shiga toxin. Typical manifestations are edema, hypertension, bleedings and severe renal failure. This last feature is more severe than in the others microangiopathic disorders [13].

The treatment of HELLP syndrome consists of the delivery of the placenta. Nevertheless, the aim of treatment is prolongation of pregnancy and symptomatic therapy if deterioration or first signs appear after delivery. Hypotensive drugs and seizure prophylaxis with magnesium sulfate represent the cornerstones of the treatment. The effectiveness of dexamethasone is not clearly defined [14]. However, some research demonstrated that postpartum plasma exchange therapy improves treatment outcomes in patients with severe HELLP syndrome [11,15-17]. Patients who do not show improvement of platlets and ASAT levels within the first 24 to 48 hours after delivery and patients with renal or neurological involvement may have benefit from plasma-exchange between 24 and 72 hours postpartum as shown by Simetka et al. [18].

Antepartum plasmapheresis for HELLP Syndrome was first described by Martin et al. seven gravidas between 24 and 30 weeks of gestation with severe preeclampsia were recruited for the treatment from 1984 to 1987. Maternal-fetal deterioration required cesarean delivery in all cases within 48 hours of therapy. There was one case of HELLP syndrome in the 24th week of pregnancy. She developed eclampsia as her third plasma exchange was performed [19].

The application of plasmapheresis/plasma exchange therapy during pregnancy in the following 30 years produced no encouraging results.

More recently, the use of extracorporeal apheresis was reported with success from Thadhani et al. in patients with preeclampsia and elevated levels of sFlt-1 levels $[20,21]$. The authors described a treatment that reduces circulating sFlt- 1 levels. They treated first 8 women with whole blood apharesis and then 11 patients with plasma- specific dextran sulfate column.

There is mounting evidence about the involvement of sFlt- 1 in the pathogenesis of human preeclampsia [22]. Other mediators like soluble endoglin show an important role espacially in the pathogenesis of HELLP Syndrome [8,22].

Thadhani et al. were not able to refute the possibility that the removal of other factors may also confer benefit to the patients. The use of ligand-specific apheresis columns (eg. configured with antisFlt-1 antibody or VEGF) could determine the relative contribution of sFlt-1 depletion versus depletion of other potential mediators of preeclampsia in further studies.

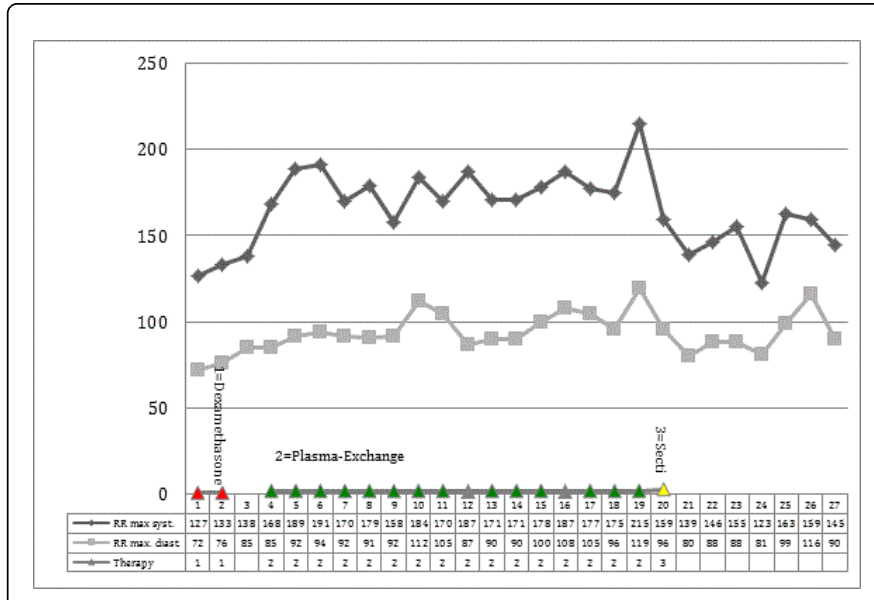

Figure 1: Maximum values of blood pressure in $\mathrm{mmHG}$ for each day of hospitalization. Therapy:Day 1-2(red) Dexamethason, Day 4-19 (green) Plasmapheresis, Day 20 (yellow) caesarean section.

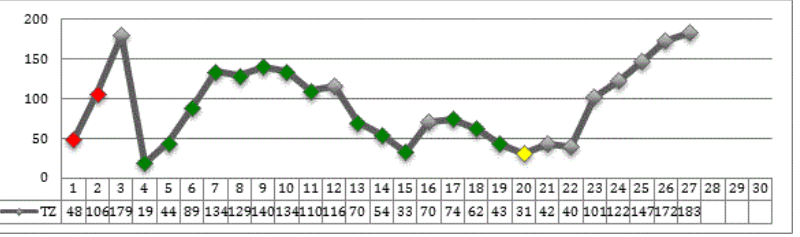

Figure 2: Platelets count (platelets/nl) for each day of hospitalization. Therapy:Day 1-2(red) Dexamethason, Day 4-19 (green) Plasmapheresis, Day 20 (yellow) caesarean section.

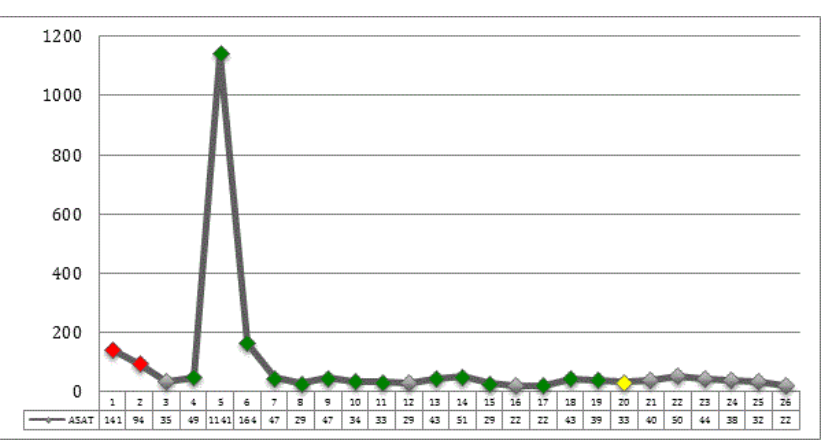

Figure 3: ASAT (U/L) for each day of hospitalization. Therapy: Day 1-2(red) Dexamethason, Day 4-19 (green) Plasmapheresis, Day 20 (yellow) caesarean section.

To our knowledge, our is the second reported case with plasma exchange for treatment of prepartum HELLP syndrome, the first before the 20 week of pregnancy with a prolongation of the gestation of more than 14 days.

Under the treatment, we reported an increase of the platlet count and a reduction of the liver enzymes (Figures 2 and 3). Plasma exchange therapy had no influence on blood pressure. Thadani et al. also reported no significant blood pressure changes in their studies and 
Citation: lannaccone A, Tyczynski B, Birdir C, Enekwe A, Kimmig R, et al. (2016) The Use of Plasma Exchange in a Very Early-onset and Life Threatening, Hemolysis, Elevated Liver Enzymes, and Low Platelet (HELLP) Syndrome: A Case Report. Gynecol Obstet (Sunnyvale) 6: 387. doi:10.4172/2161-0932.1000387

Page 4 of 4

explained this by the renal endothelial cell damage implicated in the pathomechanism of gestational hypertension. The time required to heal this lesion may be the reason for the delayed response to the therapy.

Unfortunately, we failed to prolong pregnancy until the baby could survive after the delivery. An explanation for the limited effect may be the progession of endothelial damage which cannot inhibit by plasmepheresis. However, considering the very early onset of the HELLP syndrome and a prolongation of pregnancy of 20 days in total, plasmapheresis appears to be a promising and safe therapeutic approach to prolong pregnancy in early onset preeclampsia as well as in early onset HELLP syndrome.

\section{Acknowlegment}

Thanks to all the colleagues of the department of OB/Gyn and internal medicine involved in the management of this case.

\section{Disclosure of Interests}

No author has any conflict of interest to disclose.

\section{Contribution to Authorship}

All authors were involved in the conception of the work as well in the critical revision. The first author also wrote the paper.

\section{References}

1. Haram K, Svendsen E, Abildgaard U (2009) The HELLP syndrome clinical issues and management. A Review. BMC Pregnancy Childbirth 9: 8.

2. Sibai BM, Ramadan MK, Usta I, Salama M, Mercer BM, et al. (1993) Maternal morbidity and mortality in 442 pregnancies with hemolysis, elevated liver enzymes, and low platelets (HELLP syndrome). Am J Obstet Gynecol 169: 1000-1006.

3. Magann EF, Martin JN Jr (1999) Twelve steps to optimal management of HELLP syndrome. Clin Obstet Gynecol 42: 532-550.

4. Alsulyman OM, Castro MA, Zuckerman E, McGehee W, Goodwin TM, et al. (1996) Preeclampsia and liver infarction in early pregnancy associated with the antiphospholipid syndrome. Obstet Gynecol 88: 644-646.

5. Ellison J, Sattar N, Greer I (1999) HELLP syndrome: mechanisms and management. Hosp Med 60: 243-249.

6. Isler CM, Rinehart BK, Terrone DA, Martin RW, Magann EF, et al. (1999) Maternal mortality associated with HELLP (hemolysis, elevated liver enzymes, and low platelets) syndrome. Am J Obstet Gynecol 181: 924-928.
7. Gul A, Cebeci A, Aslan H, Polat I, Ozdemir A, et al. (2005) Perinatal outcomes in severe preeclampsia-eclampsia with and without HELLP syndrome. Gynecol Obstet Invest 59: 113-118.

8. Abildgaard U, Heimdal K (2013) Pathogenesis of the syndrome of hemolysis, elevated liver enzymes, and low platelet count (HELLP): a review. Eur J Obstet Gynecol Reprod Biol 166: 117-123.

9. Sircar M, Thadhani R, Karumanchi SA (2015) Pathogenesis of preeclampsia. Curr Opin Nephrol Hypertens 24: 131-138.

10. Weinstein L (1982) Syndrome of hemolysis, elevated liver enzymes, and low platelet count: a severe consequence of hypertension in pregnancy. Am J Obstet Gynecol 142: 159-167.

11. Eser B, Guven M, Unal A, Coskun R, Altuntas F, et al. (2005) The role of plasma exchange in HELLP syndrome. Clin Appl Thromb Hemost 11: 211-217.

12. Kaplan AA (1990) A simple and accurate method for prescribing plasma exchange. ASAIO Trans 36: M597-599.

13. Sibai BM (2009) Imitators of severe pre-eclampsia. Semin Perinatol 33: 196-205.

14. Fonseca JE, Méndez F, Cataño C, Arias F (2005) Dexamethasone treatment does not improve the outcome of women with HELLP syndrome: a double-blind, placebo-controlled, randomized clinical trial. Am J Obstet Gynecol 193: 1591-1598.

15. Erkurt MA, Berber I, Berktas HB, Kuku I, Kaya E, et al. (2015) A lifesaving therapy in Class I HELLP syndrome: Therapeutic plasma exchange. Transfus Apher Sci 52: 194-198.

16. Martin JN Jr, Files JC, Blake PG, Perry KG Jr, Morrison JC, et al. (1995) Postpartum plasma exchange for atypical preeclampsia-eclampsia as HELLP (hemolysis, elevated liver enzymes, and low platelets) syndrome. Am J Obstet Gynecol 172: 1107-1125.

17. Vafaeimanesh J, Nazari A, Hosseinzadeh F (2014) Plasmapheresis: Lifesaving treatment in severe cases of HELLP syndrome. Caspian J Intern Med 5: 243-247.

18. Simetka O, Klat J, Gumulec J, Dolezalkova E, Salounova D, et al. (2015) Early identification of women with HELLP syndrome who need plasma exchange after delivery. Transfus Apher Sci 52: 54-59.

19. Martin JN Jr, Perry KG Jr, Roberts WE, Norman PF, Files JC, et al. (1994) Plasma exchange for preeclampsia: II. Unsuccessful antepartum utilization for severe preeclampsia with or without HELLP syndrome. J Clin Apher 9: 155-161.

20. Thadhani R, Kisner T, Hagmann H, Bossung V, Noack S, et al. (2011) Pilot study of extracorporeal removal of soluble fms-like tyrosine kinase 1 in preeclampsia. Circulation 124: 940-950.

21. Thadhani R, Hagmann H, Schaarschmidt W, Roth B, Cingoez T, et al. (2016) Removal of Soluble Fms-Like Tyrosine Kinase-1 by Dextran Sulfate Apheresis in Preeclampsia. J Am Soc Nephrol 27: 903-913.

22. Levine RJ, Lam C, Qian C, Yu KF, Maynard SE, et al. (2006) Soluble endoglin and other circulating antiangiogenic factors in preeclampsia. $\mathrm{N}$ Engl J Med 355: 992-1005. 